\title{
Update on the ongoing outbreak of haemolytic uraemic syndrome due to Shiga toxin-producing Escherichia coli (STEC) serotype 0104, Germany, May 2011
}

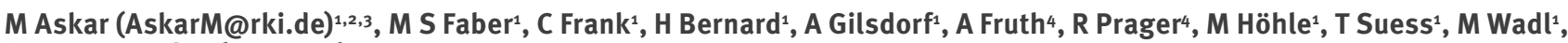

G Krause ${ }^{1}$, K Stark ${ }^{1}$, D Werber ${ }^{1}$

1. Robert Koch Institute, Berlin, Germany

2. Postgraduate Training for Applied Epidemiology (PAE, German Field Epidemiology Training Programme), Robert Koch Institute, Department for Infectious Disease Epidemiology, Berlin, Germany

3. European Programme for Intervention Epidemiology Training (EPIET), European Centre for Disease Prevention and Control (ECDC), Stockholm, Sweden

4. National Reference Centre for Salmonella and other Bacterial Enteric Pathogens, Robert Koch Institute, Wernigerode, Germany

Citation style for this article:

Askar M, Faber MS, Frank C, Bernard H, Gilsdorf A, Fruth A, Prager R, Höhle M, Suess T, Wadl M, Krause G, Stark K, Werber D. Update on the ongoing outbreak of

haemolytic uraemic syndrome due to Shiga toxin-producing Escherichia coli (STEC) serotype 0104, Germany, May 2011.

Euro Surveill. 2011;16(22):pii=19883. Available online: http://www.eurosurveillance.org/ViewArticle.aspx?Articleld=19883

Article published on 2 June 2011

Since early May 2011, a large outbreak of haemolytic uraemic syndrome (HUS) and bloody diarrhoea related to infections with Shiga toxin-producing Escherichia coli (STEC) has been observed in Germany. The outbreak is focused in the north, but cases have been reported from all German states and other countries. Since our report last week, the number of HUS cases has increased to 470 and STEC serotype 0104 has been confirmed in many cases.

\section{Description of the ongoing outbreak}

Since the beginning of May 2011, 470 cases of haemolytic uraemic syndrome HUS have been notified to the Robert Koch Institute (RKI). Our initial findings have been presented [1], including background information on STEC infections and HUS. The clinical and laboratory case definitions used are available [2]. Here we give an update on the epidemiological characteristics of the outbreak concerning cases of STEC and HUS notified to the Robert Koch Institute as of 31 May 2011.

Of 470 HUS cases, 273 (58\%) were clinical cases with laboratory confirmation of Shiga toxin-producing Escherichia coli (STEC) infection. The German National Reference Centre for Salmonella and other Bacterial Enteric Pathogens alone has detected STEC serotype 0104, Shiga toxin 2 (stx2)-positive, intimin (eae)-negative in more than 60 samples from cases in the outbreak, indicating that this unusual serotype is the cause of the outbreak.

\section{Geographical distribution of HUS cases}

Cases of HUS have been notified from all German Federal states. The highest cumulative incidence of HUS, since 1 May 2011, continues to be observed in the five northern states: Hamburg, SchleswigHolstein, Bremen, Mecklenburg-Vorpommern and
Lower Saxony (Table). A total of $66 \%$ of HUS cases have been notified from these states.

\section{Epidemiological development}

From 1 to 8 May 2011, the number of new HUS cases was between one and two cases per day, based on the

\section{TABLE}

Notified cases and cumulative incidence of HUS since 1 May 2011, Germany $(n=470)$

\begin{tabular}{|l|c|c|}
\hline Federal State & $\begin{array}{c}\text { Number of } \\
\text { HUS cases }\end{array}$ & $\begin{array}{c}\text { Cumulative } \\
\text { incidence } \\
\text { (per 100,000 } \\
\text { population) }\end{array}$ \\
\hline Hamburg & 97 & 5.47 \\
\hline Schleswig-Holstein & 121 & 4.27 \\
\hline Bremen & 22 & 3.32 \\
\hline Mecklenburg-Vorpommern & 51 & 1.21 \\
\hline Lower Saxony & 33 & 0.64 \\
\hline Hesse & 5 & 0.54 \\
\hline Saarland & 75 & 0.49 \\
\hline North Rhine-Westphalia & 9 & 0.42 \\
\hline Berlin & 4 & 0.26 \\
\hline Saxony-Anhalt & 3 & 0.17 \\
\hline Thuringia & 13 & 0.13 \\
\hline Baden-Württemberg & 3 & 0.12 \\
\hline Brandenburg & 4 & 0.12 \\
\hline Rhineland-Palatinate & 0.10 \\
\hline Bavaria & 37 & 0.07 \\
\hline Saxony & 3 & 0.02 \\
\hline Total & 3 & 0.57 \\
\hline
\end{tabular}

HUS: haemolytic uraemic syndrome.

Data as of 31 May 2011, 3 pm. 
date of onset of diarrhoea (Figure 1). From 9 May, we observed an initially steady increase in the number of cases. This increase gained in intensity over the following days and reached a maximum of 39 notified HUS cases on 16 May.

\section{Age and sex distribution of HUS cases}

As reported on 26 May 2011 [1], the age and sex distribution of HUS cases remain conspicuous: the majority of patients were aged 20 years or older (88\%) and female (71\%). Notably, between 2006 and 2010, the proportion of adults in reported STEC and HUS cases was only between $1.5 \%$ and $10 \%$, and there were no marked differences in sex distribution [3]. Figure 2 shows the age- and sex-specific cumulative incidence of notified cases of HUS since 1 May 2011.

\section{Fatal cases}

To date, 13 deaths have been notified: in nine cases, the deaths were in connection with HUS; in the remainder, the cases had had symptomatic STEC infection that was laboratory confirmed. The cases who died were between 22 and 91 years of age: five were aged between 22 and 40 years and eight between 75 and 91 years of age.

\section{Foreign cases with connection}

to the present outbreak

Further HUS cases have been communicated from Denmark, United Kingdom, France, Netherlands, Norway, Austria, Spain, Sweden (including one death),
Switzerland and the United States. Nearly all of these cases had a travel history to northern Germany. For some cases, however, detailed investigations are ongoing. After a stay in northern Germany between 8 and 10 May 2011, 15 members of a Swedish travel group (30 members in total) developed symptoms of STEC infection and HUS was diagnosed in five of these cases.

\section{Evaluation of the situation}

The present situation marks one of the largest outbreaks ever described of HUS worldwide, and the largest outbreak ever reported in Germany. Because of the delay in notification and reporting of cases, the current notification data cannot be interpreted as a decrease in case numbers.

The age and sex distribution of cases in this outbreak is highly unsual, as is the identified outbreak strain: STEC 0104, Shiga toxin 2 (stx2)-positive, intimin (eae)negative. Serotype STEC 0104 has caused food-borne outbreaks of diarrhoea and HUS, or isolated cases of HUS before $[4,5]$, but is not known to have caused previous outbreaks in Germany.

\section{Current epidemiological activities}

RKI is currently conducting the following studies to further investigate the outbreak:

- representative online survey within the German population to describe the disease burden;

\section{FIGURE 1}

Notified cases of HUS by date of onset of diarrhoea (only cases with a notified date of onset since 1 May 2011), Germany $(\mathrm{n}=421)$

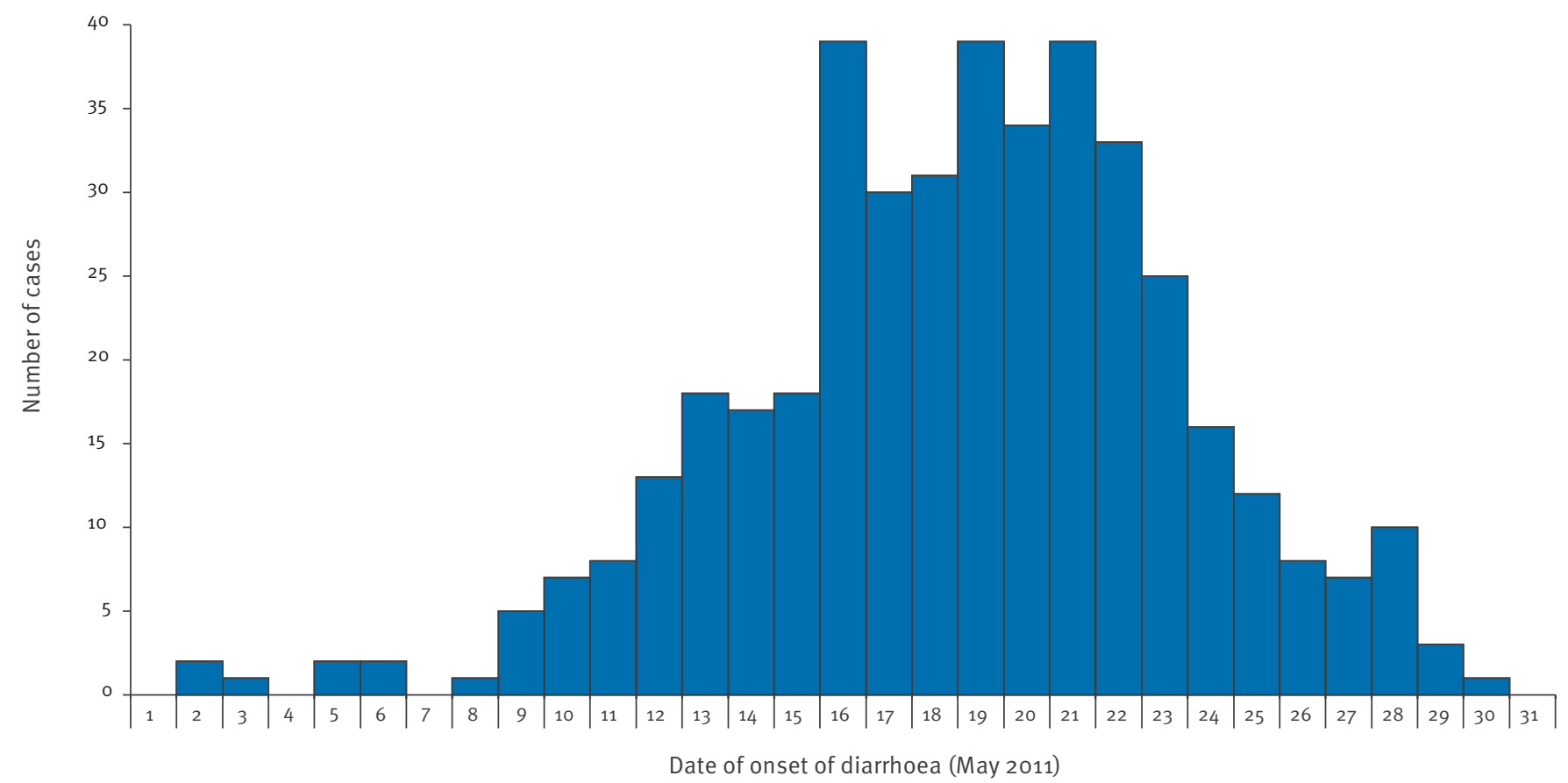

HUS: haemolytic uraemic syndrome.

Data as of 31 May 2011, 3 pm. 
- case-control study in heavily affected hospitals, in Lübeck (in Schleswig-Holstein) and Hamburg;

- case-control study in hospitals that have observed a recent increase in cases numbers and had not been previously affected;

- analyses of questionnaires on cases completed by nephrologists treating the cases;

- Investigation of human-to-human transmission (and of information about purchases made by analysis of till receipts) within the setting of a special outbreak in a canteen;

- cohort investigations of various groups, in which several members developed symptoms of STEC infection after dinner in a restaurant (the members of the groups are questioned about the food products they consumed);

- exploration of several events and festivities that can be related to cases.

Furthermore, the RKI is cooperating with colleagues from Sweden and Denmark, who are performing cohort studies of groups in which several members developed symptoms of STEC infection.

The Federal Institute for Risk Assessment (BfR) has recommended that consumers in Germany abstain from eating raw tomatoes, cucumbers and leafy salads (based on results from an epidemiological study, conducted by the RKI in cooperation with regional and local health departments from Hamburg [1]). As long as the studies outlined above do not lead to new evidence and as long as the outbreak is still ongoing, these recommendations - concerning goods available in northern Germany in particular - remain in effect.

\section{Acknowledgments}

We gratefully acknowledge the contribution of all local and state health departments, whose investigations and notifications were the data basis of this report, as well as the

\section{FIGURE 2}

Cumulative incidence of HUS cases notified since

1 May 2011, by age and sex, Germany $(n=470)$

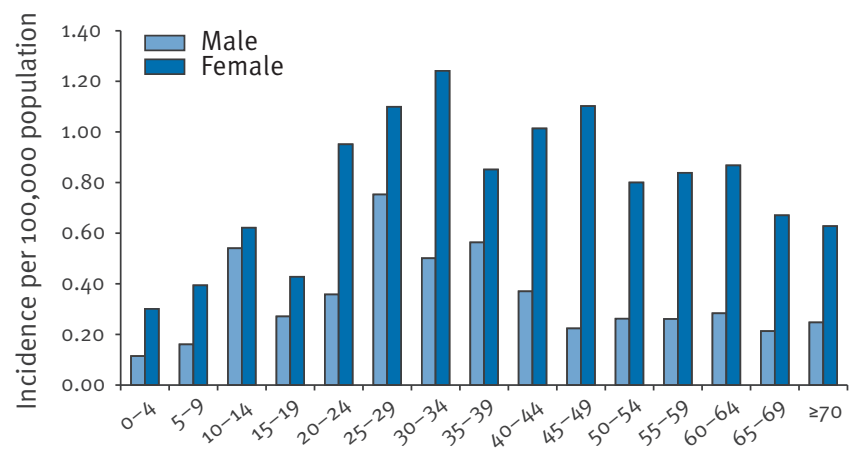

Age group (years)

HUS: haemolytic uraemic syndrome.

Data as of 31 May 2011, 3 pm. contribution of the health authorities of other European countries affected by the outbreak.

References

1. Frank C, Faber MS, Askar M, Bernard H, Fruth A, Gilsdorf $A$, et al. Large and ongoing outbreak of haemolytic uraemic syndrome, Germany, May 2011. Euro Surveill. 2011;16(21): pii=19878. Available from: http://www. eurosurveillance.org/ViewArticle.aspx?Articleld $=19878$

2. Robert Koch Institute (RKI). Case definition for HUS-cases associated with the outbreak in the spring 2011 in Germany. HUS-Outbreak_Case-Definition_2011-06-01_ENG.doc . Available from: http://www.rki.de/cln_116/nn_217400/EN/ Home/HUS Case definition,templateld $=$ raw, property $=$ publi cationFile.pdff/HUS_Case_definition.pdf

3. Robert Koch Institute (RKI). SurvStat@RKI. Berlin:.RKI. [Accessed 24 May 2011]. German. Available from: http://www3. rki.de/SurvStat

4. Bea WK, Lee YK. Cho MS, Ma SK, Kim SW, Kim NH, et al. A case of hemolytic uremic syndrome caused by Escherichia coli 104: $\mathrm{H}_{4}$.

Yonsei Med J. 2006;47(3):437-9.

5. Centers for Disease Control and Prevention (CDC). Outbreak of acute gastroenteritis attributable to Escherichia coli serotype 0104:H21--Helena, Montana, 1994. MMWR Morb Mortal Wkly Rep. 1995;44(27):501-3. 